\title{
Activation of Mo/HZSM-5 for methane aromatization
}

\author{
Christiaan H. L. Tempelman, Xiaochun Zhu, Emiel J. M. Hensen* \\ Laboratory of Inorganic Materials Chemistry, Schuit Institute of Catalysis, Eindhoven University of Technology, Den Dolech 2, 5612 AZ Eindhoven, \\ The Netherlands
}

\section{A R T I C L E I N F}

\section{Article history:}

Received 7 December 2014

Accepted 29 January 2015

Published 20 June 2015

\section{Keywords:}

Methane aromatization

Molybdenum

HZSM-5

Pretreatment

Carburization

Silylation

\begin{abstract}
A B S T R A C T
The effect of Mo/HZSM-5 pretreatment at $973 \mathrm{~K}$ in inert (He), oxidizing (artificial air), and carburizing $\left(\mathrm{CH}_{4} / \mathrm{He}\right.$ mixture $)$ atmospheres on its performance in non-oxidative methane dehydroaromatization (MDA) was investigated. The effect of post-synthesis silylation on deactivation of external acid sites was also studied. Precarburization resulted in increased aromatic selectivity and improved catalyst stability. The benzene selectivity was the highest for the silylated Mo/HZSM-5 catalyst (benzene + naphthalene selectivity after $1 \mathrm{~h}$ on stream was close to $100 \%$ ). The deactivation of precarburized zeolites was less pronounced than that of zeolites heated in air or He. During heating in air or He, larger fractions of the molybdenum oxide species diffused into the micropores than during heating in methane. Carburization of the molybdenum oxide species in the micropores during MDA resulted in the formation of molybdenum carbide particles, and these contributed to pore blocking, making the Brønsted acid sites inaccessible. The formation of molybdenum carbides during heating in methane resulted in a less mobile Mo phase. It is argued that the presence of molybdenum carbide particles in the micropores contributes to rapid catalyst deactivation, in addition to the formation of hard coke on the external surface.
\end{abstract}

(C) 2015, Dalian Institute of Chemical Physics, Chinese Academy of Sciences. Published by Elsevier B.V. All rights reserved.

\section{Introduction}

Because petroleum oil reserves are dwindling, the identification of alternative feedstocks for fuels and chemical production is necessary. Natural gas is increasingly considered as a feedstock for energy, fuels, and chemicals, because it is abundant and the cleanest of all fossil resources. In the 2013 BP Statistical Review of World Energy, it was reported that proven natural gas reserves amount to approximately 180 trillion $\mathrm{m}^{3}$ [1]. Large amounts of these natural gas reserves are located in remote areas, which makes their valorization costly. In addition to direct liquefaction, there are several options for the large-scale conversion of natural gas to liquefied fuels via the syngas platform (a mixture of $\mathrm{H}_{2}$ and $\mathrm{CO}$ ). These include methanol synthesis, dimethyl ether synthesis, and
Fischer-Tropsch synthesis [2-4]. Facilities that produce syngas are capital intensive; only large-scale syngas production is cost effective [5]. A long-term goal of the chemical industry is therefore to develop alternative routes for directly converting methane to easily transportable liquid intermediates that can serve as platforms for fuels and chemicals. The direct oxidation of methane to methanol is a significant scientific challenge. Non-oxidative methane dehydroaromatization (MDA), which converts methane to aromatics, mainly benzene, and hydrogen, is more promising than oxidative approaches.

MDA was first described by Wang et al. [6], and has since been widely investigated by industry and academia. Catalyst screening has shown that Mo/HZSM-5 is the preferred catalyst for MDA [7-9]. The molybdenum oxide phase is carburized by $\mathrm{CH}_{4}$ to a molybdenum carbide $\left(\mathrm{MoC}_{x}\right)$ phase. Although the exact

\footnotetext{
* Corresponding author. Tel: +31-40-2475178; E-mail: e.j.m.hensen@tue.nl This work was supported by the European Union through the EU-FP7 NEXT-GTL consortium (NMP3-LA-2009-229183). DOI: 10.1016/S1872-2067(14)60301-6 | http://www.sciencedirect.com/science/journal/18722067 | Chin. J. Catal., Vol. 36, No. 6, June 2015
} 
nature of this carbide phase has not been determined, its function is to convert methane to ethylene $[10,11]$, which is then oligomerized and cyclized to aromatic compounds at the Brønsted acid sites (BASs) of the zeolite. The harsh process conditions, with typical temperatures of $973 \mathrm{~K}$ and above, necessary for the activation of methane [12] result in poor catalyst stability; industrial applications of this reaction are therefore challenging. The poor catalyst stability is mainly caused by the formation of carbonaceous deposits, which block the zeolite micropores [13].

The BASs located at the external surface are considered to be involved in the formation of large amounts of carbonaceous deposits [14]. These BASs catalyze the formation of polycyclic aromatic hydrocarbons [15], which are deposited on the external surface and eventually block the entrances to the micropores [16-24]. The results of our comprehensive study of catalyst deactivation in MDA suggested that the formation of a polycyclic carbon layer around the zeolite crystal with progressive time on stream was the main reason [25]. It has also been reported that deactivation of the external surface BASs suppresses the formation of coke during MDA [21-24].

The pretreatment procedure used to activate the Mo/HZSM-5 catalyst strongly influences the catalytic performance. The pretreatment gas directly affects the state of the Mo phase and indirectly affects the state of the zeolite at the start of the reaction [26-28]. Although a significant number of studies include data on catalyst activation [7,26-34], comprehensive studies are lacking; comparisons among available studies is greatly hampered by the often very different reaction conditions and differences among catalyst samples. Two studies $[28,33]$ have directly compared the influence of the pretreatment procedure, but they were conducted at lower weight hourly space velocity (WHSV) values than those typically used in MDA. In the present study, we systematically compared the influence of the gas (inert He, oxidizing artificial air, and reducing/carburizing $\mathrm{CH}_{4}$ ) used for catalyst activation on the catalytic MDA performance. As we showed previously, catalyst silylation significantly affects the MDA performance [24], therefore we determined the influence of catalyst pretreatment on fresh and silylated samples. We showed that precarburization resulted in improved catalytic performance (improved catalyst stability and increased benzene selectivity) for silylated and non-silylated Mo/ZSM-5. We determined the detailed physicochemical properties of the fresh, carburized, and spent catalysts.

\section{Experimental}

\subsection{Synthesis of materials}

The parent NH4ZSM-5 was obtained from Akzo-Nobel (now Albemarle Catalysts). The parent zeolite had a $\mathrm{Si} / \mathrm{Al}$ ratio of 19.4, determined by inductively coupled plasma optical emission spectroscopy (ICP-OES). Mo was introduced by incipient wetness impregnation with an aqueous solution of ammonium heptamolybdate tetrahydrate (Merck) of appropriate concentration. Prior to impregnation, the zeolite was dried overnight at $383 \mathrm{~K}$. After impregnation, the samples were dried for $1 \mathrm{~h}$. The target Mo content was $4 \mathrm{wt} \%$. The Mo-containing zeolites were calcined in artificial air at $823 \mathrm{~K}$ for $5 \mathrm{~h}$ after heating at a rate of $1.5 \mathrm{~K} / \mathrm{min}$. The parent ZSM-5 zeolite is denoted by HZSM-5. The zeolite after Mo introduction is denoted by Mo/HZSM-5.

A method based on that reported by Zheng et al. [35] was used to silylate the external surfaces of the zeolites. Typically, Mo/HZSM-5 (2 g) was dried overnight at $373 \mathrm{~K}$ and dispersed in $n$-hexane $(50 \mathrm{~mL})$. Tetraethyl orthosilicate (TEOS, $0.3 \mathrm{~mL}$; Merck) was added and the suspension was stirred for $1 \mathrm{~h}$ under reflux. The amount of TEOS corresponded to $0.4 \mathrm{wt} \%$ of the zeolite. After silylation, the zeolite was filtered, dried overnight at $373 \mathrm{~K}$, and calcined in artificial air. The catalyst was first heated at a rate of $2 \mathrm{~K} / \mathrm{min}$ to $393 \mathrm{~K}$, followed by an isothermal period of $2 \mathrm{~h}$. The temperature was then further increased to $773 \mathrm{~K}$ at a rate of $0.2 \mathrm{~K} / \mathrm{min}$. The catalyst was kept at this temperature for $4 \mathrm{~h}$. The silylated Mo/HZSM-5 zeolite is denoted by Mo/HZSM-5(Si).

Prior to the MDA reaction, the catalyst was heated to $973 \mathrm{~K}$ at a rate of $10 \mathrm{~K} / \mathrm{min}$ in He, artificial air, or an $80 \% / 20 \%(\mathrm{v} / \mathrm{v}$ ) $\mathrm{CH}_{4} / \mathrm{He}$ flow. In addition to activity testing, another set of samples was prepared by rapidly cooling the catalyst after pretreatment in a He flow. The catalyst was transported under exclusion of air into a $\mathrm{N}_{2}$-filled glove-box. The activation procedure is indicated by adding the gas type as a suffix to the sample name.

\subsection{Catalyst characterization}

The Mo and $\mathrm{Al}$ contents of the samples were determined by ICP-OES, using a Spectro CIROS CCD spectrometer equipped with a free-running $27.12 \mathrm{MHz}$ generator running at $1400 \mathrm{~W}$. Prior to analysis, the samples were dissolved in a mixture of $\mathrm{HF} / \mathrm{HNO}_{3} / \mathrm{H}_{2} \mathrm{O}(1: 1: 1)$.

Ar sorption isotherms were measured at $87 \mathrm{~K}$, using a Micromeritics ASAP2020 system in static measurement mode. The samples were outgassed at $623 \mathrm{~K}$ for $8 \mathrm{~h}$ prior to the sorption measurements. BET equation was used to calculate the specific surface area $\left(S_{\mathrm{BET}}\right)$ from the adsorption data obtained $\left(p / p_{0}=0.05-0.25\right)$. The mesopore volume $\left(V_{\text {meso }}\right)$ and the mesopore size distribution were determined, using the BJH method, from the adsorption branch of the isotherm. The micropore area $\left(S_{\text {micro }}\right)$ and the micropore volume $\left(V_{\text {micro }}\right)$ were determined using the $t$-plot method, at a thickness range between 3.5 and $5.4 \AA$ [36].

Infrared (IR) spectra were recorded in the 4000-400 $\mathrm{cm}^{-1}$ range using a Bruker Vertex $70 \mathrm{~V}$ spectrometer. Samples were pressed into a self-supporting wafer of typical density 8 $\mathrm{mg} / \mathrm{cm}^{2}$. Adsorbed water was removed by evacuating the sample at $773 \mathrm{~K}$ for $2 \mathrm{~h}$. After evacuation, the sample was cooled to $323 \mathrm{~K}$, and then the background spectrum was recorded. The total concentration of BASs was determined by IR spectroscopy of adsorbed pyridine. The dehydrated zeolite wafer was cooled to $323 \mathrm{~K}$ and exposed to pyridine until the bands related to pyridine were saturated. The sample was then evacuated at $423 \mathrm{~K}$ for $2 \mathrm{~h}$ and the spectrum was recorded. The spectra were 
deconvoluted by standard procedures, and the extinction coefficient values reported by Datka et al. [37] were used for quantification.

Ultraviolet (UV) Raman spectra were recorded using a Jobin-Yvon T64000 triple-stage instrument with a spectral resolution of $2 \mathrm{~cm}^{-1}$. The excitation laser line at $325 \mathrm{~nm}$ was produced by a Kimmon He-Cd laser. The power of the laser on the sample was $4 \mathrm{~mW}$.

Magic angle spinning (MAS) ${ }^{27} \mathrm{Al}$ single-pulse nuclear magnetic resonance (NMR) spectroscopy was performed using a Bruker Avance DMX-500 NMR spectrometer equipped with a $2.5 \mathrm{~mm}$ MAS probe head operated at an ${ }^{27} \mathrm{Al}$ NMR resonance frequency of $130.3 \mathrm{MHz}$. The ${ }^{27} \mathrm{Al}$ chemical shift was referenced to saturated $\mathrm{Al}\left(\mathrm{NO}_{3}\right)_{3}$ solution. In a typical experiment, a well-hydrated sample (10 mg) was packed in a $2.5-\mathrm{mm}$ zirconia rotor. The MAS sample rotation speed was $20 \mathrm{kHz}$. Single-pulse excitation was used, with a $180^{\circ}$ pulse of $1 \mu$ s and an interscan delay of $1 \mathrm{~s}$. The relaxation time was $1 \mathrm{~s}$ and the pulse length was $1 \mathrm{~s}$.

Transmission electron microscopy (TEM; FEI Tecnai 20) was performed at an electron-accelerating voltage of $200 \mathrm{kV}$. Typically, a small amount of sample was suspended in ethanol, sonicated, and dispersed over a $\mathrm{Cu}$ grid with a holey carbon film.

Weight-loss curves were determined for the spent catalysts after $12 \mathrm{~h}$ on stream in MDA. These measurements were carried out using a Mettler Toledo TGA/DSC 1 instrument. Samples were heated to $1023 \mathrm{~K}$ in uncovered alumina crucibles at a rate of $5 \mathrm{~K} / \mathrm{min}$ in a 33/67 $(v / v) \mathrm{O}_{2} / \mathrm{He}$ flow.

Catalytic H/D exchange between $\mathrm{C}_{6} \mathrm{H}_{6}$ and $\mathrm{C}_{6} \mathrm{D}_{6}$ was performed using a ten-channel parallel microflow reactor. Typically, the zeolite material (50 mg) was loaded into a quartz tubular reactor with an internal diameter of $4.0 \mathrm{~mm}$. The zeolites were first pelletized and sieved to $125-250 \mu \mathrm{m}$ mesh. The ten quartz tubes were then placed in the parallel setup. Before reaction, the samples were heated to $723 \mathrm{~K}$ at a rate of $5 \mathrm{~K} / \mathrm{min}$, followed by an isothermal period of $6 \mathrm{~h}$, to remove water. The reactor was then cooled to $303 \mathrm{~K}$. The reaction was started by switching the reactor feed to a gas flow containing a 90/10 $(v / v) \mathrm{C}_{6} \mathrm{H}_{6} / \mathrm{C}_{6} \mathrm{D}_{6}$ mixture. The effluent products were analyzed using mass spectrometry. The rate of H/D exchange between benzene and perdeuterobenzene was determined as a function of temperature.

\subsection{Catalytic activity measurements}

The zeolite catalyst ( $0.5 \mathrm{~g}$ ) was placed in a tubular quartz reactor of length $490 \mathrm{~mm}$ and internal diameter $4.0 \mathrm{~mm}$. The catalyst was supported on quartz wool in the isothermal zone of the oven. All gases were fed using thermal mass flow controllers. The temperature was increased at a rate of $5 \mathrm{~K} / \mathrm{min}$ to $973 \mathrm{~K}$ in a $25 \mathrm{~mL} / \mathrm{min}$ flow of $\mathrm{He}, \mathrm{CH}_{4} / \mathrm{He}$, or artificial air. The reaction was started by switching the reactor feed to a 5/95 $(v / v) \mathrm{N}_{2} / \mathrm{CH}_{4}$ mixture $\left(\mathrm{N}_{2}\right.$ was used as the internal standard $)$ at a WHSV of $1710 \mathrm{~mL} \mathrm{CH} 4 /\left(\mathrm{g}_{\text {cat }} \cdot \mathrm{h}\right)$. The products were analyzed using an online gas chromatograph (Interscience Compact GC) equipped with three channels for separate analyses of light gases [Molsieve 5A, thermal conductivity detector (TCD)], light hydrocarbons $\left[\mathrm{Al}_{2} \mathrm{O}_{3} / \mathrm{KCl}\right.$, flame ionization detector (FID)], and aromatics (Rtx-1, TCD). $\mathrm{N}_{2}$ was used as an internal standard to close the carbon balance and account for the amount of carbon deposits formed during the reaction. The carbon formation rate $r_{\text {coke }}$ was determined based on the components ethylene, ethane, propylene, propane, benzene, toluene, and naphthalene (eq. 2). The methane conversion $\left(X_{\mathrm{CH} 4}\right)$ and benzene selectivity ( $\left.S_{\mathrm{C} 6 \mathrm{H} 6}\right)$ were calculated using eqs. (1) and (3).

$$
\begin{gathered}
r_{\text {aromatic }}=\varphi_{\mathrm{N}_{2}}^{\mathrm{In}} \times \frac{\left(\frac{A_{\text {product }}^{\mathrm{TCD}}}{f_{\text {product }}^{\mathrm{TCD}}}\right)}{\left(\frac{A_{\mathrm{N}_{2}}^{\mathrm{TCD}}}{f_{\mathrm{N}_{2}}^{\mathrm{TCD}}}\right)} \times \frac{A_{\mathrm{CH}_{4}}^{\mathrm{TCD}_{\text {lightgasses }}^{\text {blanks }}}}{A_{\mathrm{CH}_{4}}^{\mathrm{TCD}_{\text {aromatics }}^{\text {blank }}}} \\
r_{\text {Coke }}=r_{\mathrm{CH}_{4}}-\sum_{n=i}\left(r_{i} \times M W_{i}\right) \\
S_{\mathrm{C}_{6} \mathrm{H}_{6}}(w t \%)=\frac{\left(r_{\mathrm{C}_{6} \mathrm{H}_{6}} \times M W_{\mathrm{C}_{6} \mathrm{H}_{6}}\right)}{\sum_{n=i}(r \times M W)_{\text {products }}} \times 100
\end{gathered}
$$

Symbols

$r_{\mathrm{CH} 4}=$ reaction rate of $\mathrm{CH}_{4}$

$r_{i}=$ formation rate of compound $i$

$\varphi_{i}{ }^{\text {In }}=$ molar flow rate of compound $i$ into the reactor

$\varphi_{i}{ }^{\text {Out }}=$ molar flow rate of compound $i$ out of the reactor

$f_{i}^{\mathrm{TCD}}=$ TCD sensitivity factor of compound $i$

$f_{i}^{\text {FID }}=$ FID sensitivity factor of compound $i$

$A_{i}=$ measured peak area of compound i in the chromatogram

\section{Results and discussion}

\subsection{Catalytic activity measurements}

Figures 1 and 2 show the time-on-stream reaction data for Mo/HZSM-5 and Mo/HZSM-5(Si) pretreated with three different gases $\left(\mathrm{CH}_{4}, \mathrm{He}\right.$, and $\left.\mathrm{O}_{2}\right)$ at $973 \mathrm{~K}$. In all cases, the methane conversion rate decreased with time on stream. The rates of deactivation of the two zeolite samples activated in $\mathrm{CH}_{4}$ were lower than those of the samples heated in air and He. The reaction data show that initially few hydrocarbons were present in the effluent stream; this observation is in line with previous reports [29,38-40]. Methane carburizes the molybdenum oxide phase during the initial stages of the reaction. As low hydrocarbon selectivity is also seen for the precarburized sample, we can conclude that carburization of the molybdenum oxide precursor during catalyst activation in methane is not complete. After this initial phase, the hydrocarbon selectivity increased. The main hydrocarbon product was benzene, and naphthalene was the main aromatic side product. The highest benzene selectivity was observed after $1 \mathrm{~h}$ on stream; the highest benzene selectivity was $65 \mathrm{wt} \%$ for the Mo/HZSM-5 samples and 80 wt $\%$ for the Mo/HZSM-5(Si) samples. In line with previously 

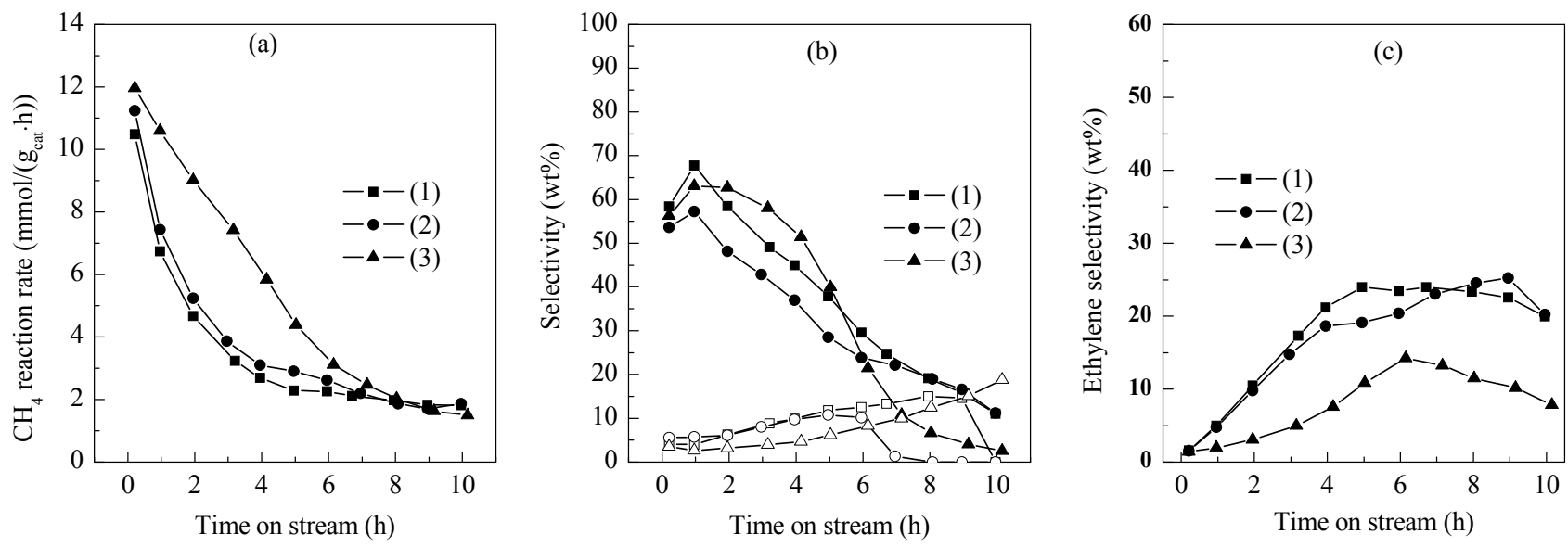

Fig. 1. MDA data for methane reaction rates (a), benzene (closed symbols) and naphthalene (open symbols) selectivities (b), and ethylene selectivities (c) for Mo/HZSM-5(air) (1), Mo/HZSM-5(He) (2), and Mo/HZSM-5( $\left.\mathrm{CH}_{4} / \mathrm{He}\right)$ (3).
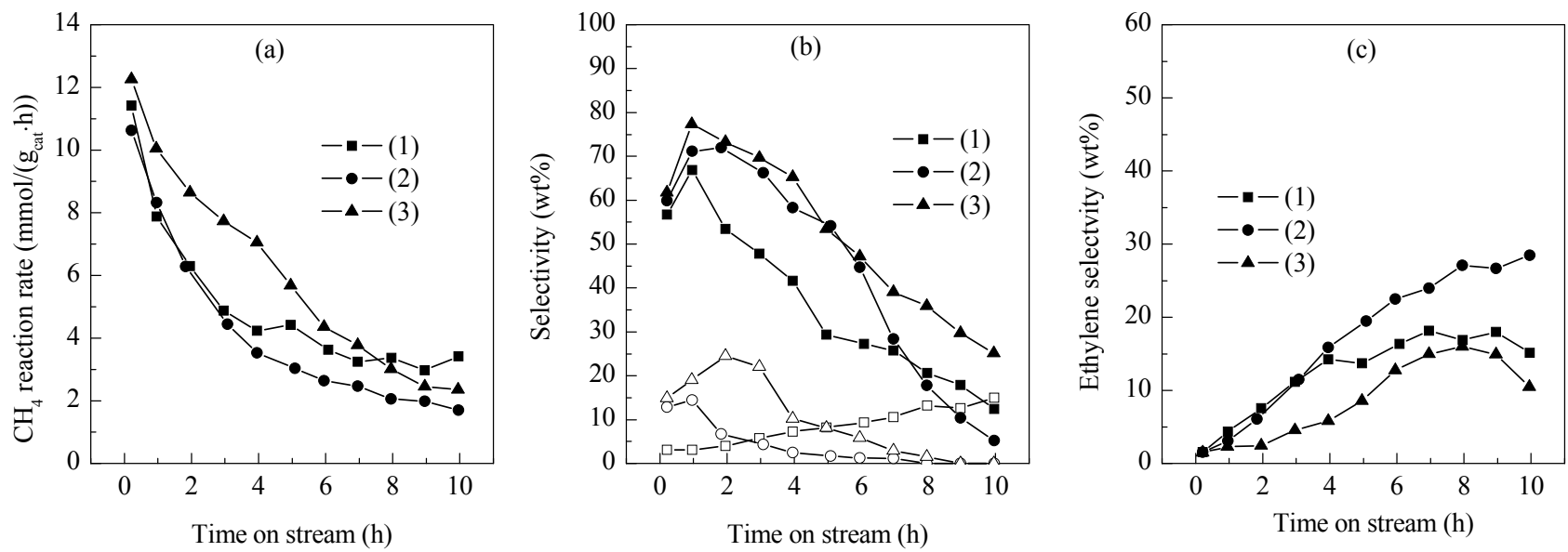

Fig. 2. MDA data for methane reaction rates (a), benzene (closed symbols) and naphthalene (open symbols) selectivities (b), and ethylene selectivities (c) for Mo/HZSM-5(Si,air) (1), Mo/HZSM-5(Si,He) (2), and Mo/HZSM-5(Si,CH $4 / \mathrm{He})$ (3).

reported data [21-24], the maximum aromatic selectivities (benzene + naphthalene selectivity) were higher for the silylated catalysts. It can also be seen that the combined selectivities for benzene and naphthalene were close to $100 \%$ for Mo/HZSM-5(Si,CH $4 / \mathrm{He})$. After $1 \mathrm{~h}$ on stream, the benzene selectivities of the catalysts pretreated in air and He decreased rapidly. In comparison, the decrease in the benzene selectivity was less pronounced for the precarburized Mo/HZSM-5 and Mo/HZSM-5(Si) catalysts. For the precarburized catalysts, the benzene selectivities started to decrease more pronouncedly only after $4 \mathrm{~h}$ on stream. The total amounts of aromatics produced were the highest for the precarburized catalysts. In all cases, the decrease in aromatic selectivity was accompanied by a substantial increase in ethylene selectivity, and a smaller increase in naphthalene selectivity. This is probably the result of deactivation of the acid sites in the micropores; this leads to higher selectivity for the intermediate product ethylene, which is formed on the molybdenum carbide phase from methane. The high naphthalene selectivity is related to the conversion of ethylene on BASs on the external surface.

\subsection{Catalyst characterization}

The textural properties of the fresh, pretreated, and spent catalysts were determined using Ar physisorption measurements. The results are shown in Table 1 . The introduction of Mo into the parent zeolite led to a decrease in the micropore volume ( $V_{\text {micro }}$ ). This is probably because of diffusion of part of the molybdenum oxide phase into the HZSM-5 micropores during calcination. The increase in the mesopore volume $\left(V_{\text {me- }}\right.$ so) is presumably the result of the damage caused by $\mathrm{Al}$ extraction from the zeolite framework [24,41]. The micropore volume of the silylated Mo/HZSM-5(Si) catalyst was smaller than that of the parent Mo/HZSM-5 zeolite. It should be stressed that silylation was performed after the Mo-loading step, which is more beneficial for the MDA reaction than the usual approach in which HZSM-5 is silylated before Mo introduction [24]. We previously showed that silylation and calcination of Mo/HZMS-5 result in higher molybdenum oxide dispersion over the external surface and an increase in the fraction of Mo entering the micropores [24]. Carburization in methane led to small decreases in the pore volumes of Mo/HZSM-5 and Mo/HZSM-5(Si). The carburization step led to the formation of different types of carbonaceous species in the catalysts. These species were investigated using thermogravimetric analysis 
Table 1

Textural properties of fresh and spent Mo/HZSM-5 and Mo/HZSM-5(Si) catalysts and chemical nature of carbon deposits.

\begin{tabular}{|c|c|c|c|c|c|c|c|c|c|c|c|}
\hline Sample & Activation & $\begin{array}{c}\text { TOS * } \\
\text { (h) }\end{array}$ & $\begin{array}{c}V_{\text {micro }} \\
\left(\mathrm{cm}^{3} / \mathrm{g}\right)\end{array}$ & $\begin{array}{c}V_{\text {meso }} \\
\left(\mathrm{cm}^{3} / \mathrm{g}\right)\end{array}$ & $\begin{array}{c}S_{\text {micro }} \\
\left(\mathrm{m}^{2} / \mathrm{g}\right)\end{array}$ & $\begin{array}{c}S_{\text {meso }} \\
\left(\mathrm{m}^{2} / \mathrm{g}\right)\end{array}$ & $\begin{array}{c}S_{\text {BET }} \\
\left(\mathrm{m}^{2} / \mathrm{g}\right)\end{array}$ & $\begin{array}{c}\mathrm{C}_{\text {total }} \\
(\mathrm{wt} \%)\end{array}$ & $\begin{array}{c}\mathrm{C}_{\mathrm{MoC}} \\
(\mathrm{wt} \%)\end{array}$ & $\begin{array}{c}\mathrm{C}_{\text {soft }} \\
(\mathrm{wt} \%)\end{array}$ & $\begin{array}{c}C_{\text {hard }} \\
\text { (wt\%) }\end{array}$ \\
\hline HZSM-5 & - & 0 & 0.12 & 0.02 & 246 & 10 & 277 & - & - & - & - \\
\hline \multirow[t]{5}{*}{ Mo/HZSM-5 } & - & 0 & 0.10 & 0.06 & 182 & 44 & 272 & - & - & - & - \\
\hline & $\mathrm{CH}_{4} / \mathrm{He}$ & 0 & 0.09 & 0.03 & 171 & 22 & 228 & 3.3 & 0.9 & 0.9 & 1.5 \\
\hline & $\mathrm{CH}_{4} / \mathrm{He}$ & 12 & 0 & 0.02 & 3 & 12 & 12 & 13.5 & 0 & 2.7 & 10.8 \\
\hline & Air & 12 & 0.02 & 0.02 & 32 & 14 & 59 & 11.7 & 0 & 3.4 & 8.3 \\
\hline & $\mathrm{He}$ & 12 & 0.02 & 0.02 & 27 & 14 & 61 & 11.1 & 0 & 3.6 & 7.5 \\
\hline \multirow[t]{5}{*}{ Mo/HZSM-5(Si) } & - & 0 & 0.07 & 0.01 & 129 & 6 & 143 & - & - & - & - \\
\hline & $\mathrm{CH}_{4} / \mathrm{He}$ & 0 & 0.05 & 0.02 & 97 & 12 & 130 & 4.5 & 1.2 & 1.8 & 1.5 \\
\hline & $\mathrm{CH}_{4} / \mathrm{He}$ & 12 & 0.03 & 0.02 & 64 & 13 & 90 & 9.5 & 0.5 & 2.4 & 6.6 \\
\hline & Air & 12 & 0.02 & 0.02 & 46 & 14 & 72 & 7.7 & 0 & 3.7 & 4.0 \\
\hline & $\mathrm{He}$ & 12 & 0.04 & 0.03 & 76 & 15 & 109 & 9.7 & 0 & 4.1 & 5.6 \\
\hline
\end{tabular}

* Time on stream in MDA.
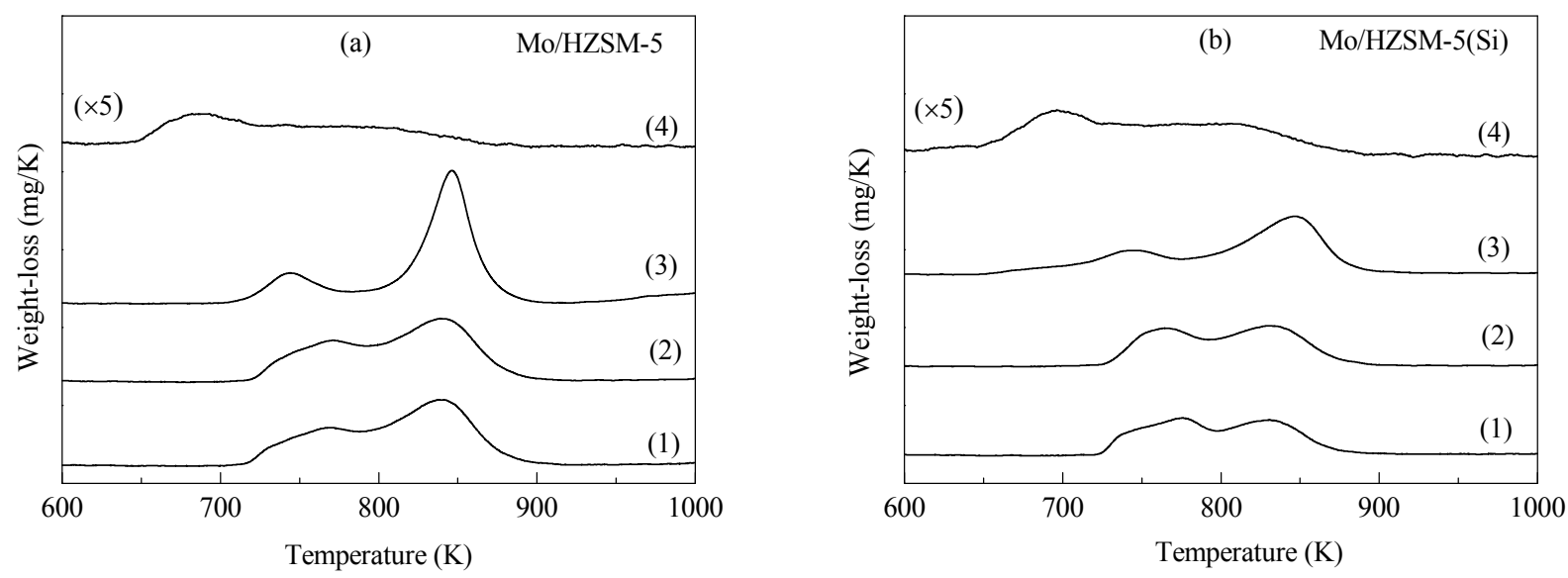

Fig. 3. TGA weight-loss curves after MDA for $12 \mathrm{~h}$ for non-silylated (a) and silylated Mo/HZSM-5 (b) catalysts pretreated in He (1), air (2), and a $\mathrm{CH}_{4} / \mathrm{He}$ mixture (3). Curve (4) corresponds to the catalyst pretreated in $\mathrm{CH}_{4} / \mathrm{He}$ and recovered from the reactor after activation (magnified $\times 5$ ).

(TGA). The TG curves of the carburized and spent Mo/HZSM-5 and Mo/HZSM-5(Si) catalysts are shown in Fig. 3. The curves display three main oxidation peaks. The main peak at $700 \mathrm{~K}$ is characteristic of oxidation of molybdenum carbide $\left(\mathrm{C}_{\mathrm{Moc}}\right)$ [42]. The second peak, at a higher temperature $(\sim 750 \mathrm{~K})$, is related to coke species formed in the proximity of molybdenum carbide [42]. This is usually amorphous polyolefinic coke and is referred to as soft coke $\left(\mathrm{C}_{\text {soft }}\right)$. The small peak at $840 \mathrm{~K}$ is related to polycyclic aromatics, referred to here as hard coke (Chard) $[19,40]$. The quantitative data obtained by deconvolution of these traces are collected in Table 1 . The TG curves for the precarburized Mo/HZSM-5 and Mo/HZSM-5(Si) catalysts contain all three types of coke. Carburization of Mo/HZSM-5(Si) led to a larger amount of carbon species associated with the Mo phase and soft coke compared with carburization of Mo/HZSM-5. This difference is in line with higher molybdenum oxide dispersion in the silylated catalyst. The decrease in the micropore volume was slightly higher for the silylated catalyst.

During MDA, the micropore volumes of the zeolite catalysts decreased substantially. The decreases in the micropore volumes of the non-silylated catalysts were greater than those of the silylated ones. This difference is consistent with the smaller amount of carbonaceous species formed in the silylated samples during the reaction. TGA of the spent samples shows that more hard coke was formed on the non-silylated catalysts. This hard coke is usually associated with the formation of polycyclic aromatics on the external surface of the zeolite $[14,15]$. Silylation effectively reduces the external acidity $[14,15]$ and, accordingly, the formation of hard coke [24]. The lower residual micropore volume of the spent non-silylated samples can therefore be correlated with high coverage of the external surface by polycyclic aromatics, which block the micropore entrances. Despite the lower rate of deactivation in MDA, the TG data show that the precarburized spent samples always contained more coke, especially in the form of hard coke, than did the samples activated in He or air. The carbon speciations for the spent samples pretreated in He and air were similar.

${ }^{27} \mathrm{Al}$ MAS NMR spectroscopy was used to determine the $\mathrm{Al}$ speciation in the samples. The NMR spectra are shown in Fig. 4. The dominant feature, at $55 \mathrm{ppm}$, is related to framework $\mathrm{Al}$ (FAl). The small peak at $0 \mathrm{ppm}$ is attributed to extraframework $\mathrm{Al}$ (EFAl). The feature at $14 \mathrm{ppm}$ also arises from EFAl, in the form of $\mathrm{Al}_{2}\left(\mathrm{MoO}_{4}\right)_{3}$. The increased EFAl concentration and the formation of aluminum molybdates observed for the Mo-modified ZSM-5 zeolites suggest dealumination of the framework. The FAl peaks for the Mo-modified zeolites are broader than that for the parent HZSM-5 zeolite. Tessonier et al. [42] attributed this broadening to a change in the symmetry 

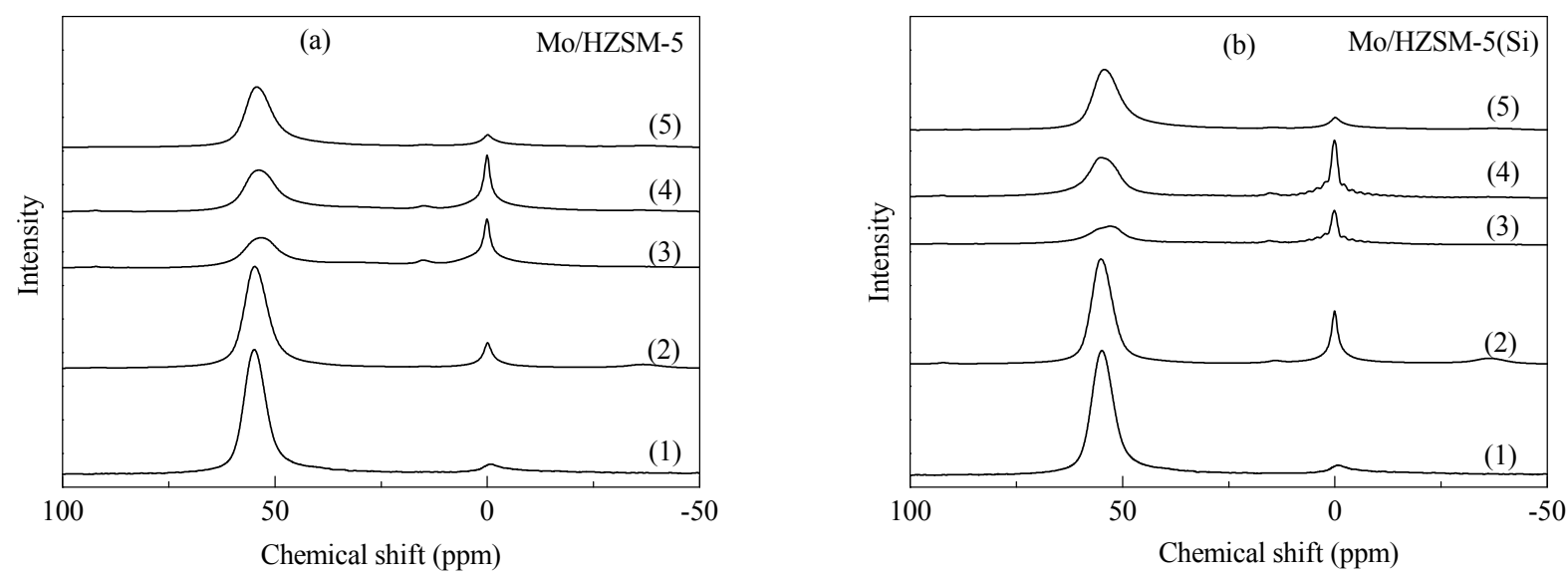

Fig. 4. ${ }^{27} \mathrm{Al}$ MAS NMR spectra of non-silylated (a) and silylated Mo/HZSM-5 (b) catalysts. (1) parent ZSM-5; (2) fresh Mo/HZSM-5 and Mo/HZSM-5 pretreated in $\mathrm{He}$ (3), air (4), and $\mathrm{CH}_{4} / \mathrm{He}$ mixture (5).

around the Al tetrahedra following exchange of protons with molybdenum oxide species. The resonance area of the FAl peak was lower for the Mo-modified samples, probably because of asymmetric Al coordination when Mo is present at the exchange sites. On carburization, the intensity of the FAl peak decreased, which indicates further dealumination. This is probably related to the high temperatures of the carburization step. The decrease in the intensity of the FAl peak was stronger when Mo/HZSM-5 or Mo/HZSM-5(Si) was treated in He or air. This suggests a higher degree of proton exchange with molybdenum oxide species at the BASs than in activation by precarburization. A portion of the EFAl is present in the form of $\mathrm{Al}_{2}\left(\mathrm{MoO}_{4}\right)_{3}$, indicated by the small peak at $14 \mathrm{ppm}$. The NMR data suggest that more $\mathrm{FAl}$ species are retained after precarburization than after pretreatment in He or air.

Before discussing the acidities of the most active precarburized samples in detail, we describe the Fourier-transform (FT)IR spectra of the activated samples. Because carbon formation resulted in blackening of the sample, FTIR experiments were only performed on the zeolites after activation in air or $\mathrm{He}$ at $973 \mathrm{~K}$. The hydroxyl stretching region of the spectra contain bands at 3745,3665 , and $3610 \mathrm{~cm}^{-1}$; these are attributed to silanols, extraframework hydroxyls, and bridging hydroxyl, respectively. As expected, modification of the parent zeolite with Mo led to a decrease in the intensity of the bridging hydroxyl band. This indicates a lower BAS density as a result of proton exchange with molybdenum oxide species. The silylated Mo/HZSM-5 contained fewer acid sites. Pretreatment of the parent and silylated Mo/HZSM-5 in He or air led to the nearly complete disappearance of all hydroxyl features, including the BASs. The acid site contents of these zeolites were also investigated using pyridine adsorption measurements (Table 2). Modification of the parent zeolite with Mo followed by silylation led to a decrease in the BAS content. After activation in He or air, the BAS content decreased further. The BAS densities for these two activated zeolites are higher than those suggested by the intensity of the bridging hydroxyl band (Fig. 5). This discrepancy can be explained by the close proximity of molybdenum oxide species to the bridging hydroxyl groups, which leads to perturbation of these hydroxyls.

The samples obtained by precarburization were investigated in more detail, because they performed substantially better than did the catalysts activated in air or He. FTIR spectroscopy of adsorbed pyridine was unsuccessful, because of the presence of carbonaceous deposits, therefore the Brönsted acidity was investigated by H/D exchange between benzene and deuterated benzene. Haw and coworkers characterized the acid sites in faujasite zeolites using ${ }^{1} \mathrm{H}$ NMR spectroscopy to track their H/D exchange with perdeuterobenzene [43]. Poduval et al. [44] used the IR spectra of H/D exchanged faujasite zeolites to determine the strengths and numbers of strong acid sites. Here, we determined the rate of $H / D$ exchange between benzene and $d_{6}$-benzene in a fixed bed reactor. A benzene to $d_{6}$-benzene ratio of 10:1 was used in the feed, and the rate of the reaction was determined by measuring the conversion of benzene to $d_{1}$-benzene. The obtained reaction rates are listed in Table 3. The exchange rates of the Mo-modified zeolites were slightly lower than that of the parent HZSM-5 zeolite. This is because of exchange of some of the protons at exchange positions with molybdenum oxide species. Carburization further decreased the reaction rate. The decrease in the acidity was the strongest for the silylated sample. After activation, only $28 \%$ of the original acidity of the HZSM-5 was retained.

\section{Table 2}

Acidities of fresh and air- and He-activated Mo/HZSM-5 and Mo/HZSM-5(Si) samples, determined from pyridine IR measurements. The air- and He-pretreated catalysts were activated at $973 \mathrm{~K}$.

\begin{tabular}{lccc}
\hline Sample & $\begin{array}{c}\text { Pretreatment } \\
\text { gas used }\end{array}$ & $\begin{array}{c}\text { BAS } \\
\left(\mathrm{mmol} / \mathrm{g}_{\text {cat }}\right)\end{array}$ & $\begin{array}{c}\text { LAS } \\
\left(\mathrm{mmol} / \mathrm{g}_{\text {cat }}\right)\end{array}$ \\
\hline HZSM-5 & - & 0.679 & 0.284 \\
Mo/HZSM-5 & - & 0.615 & 0.136 \\
& He & 0.229 & 0.055 \\
Mo/HZSM-5(Si) & Air & 0.361 & 0.197 \\
& - & 0.530 & 0.060 \\
& He & 0.278 & 0.148 \\
& Air & 0.239 & 0.145 \\
\hline
\end{tabular}



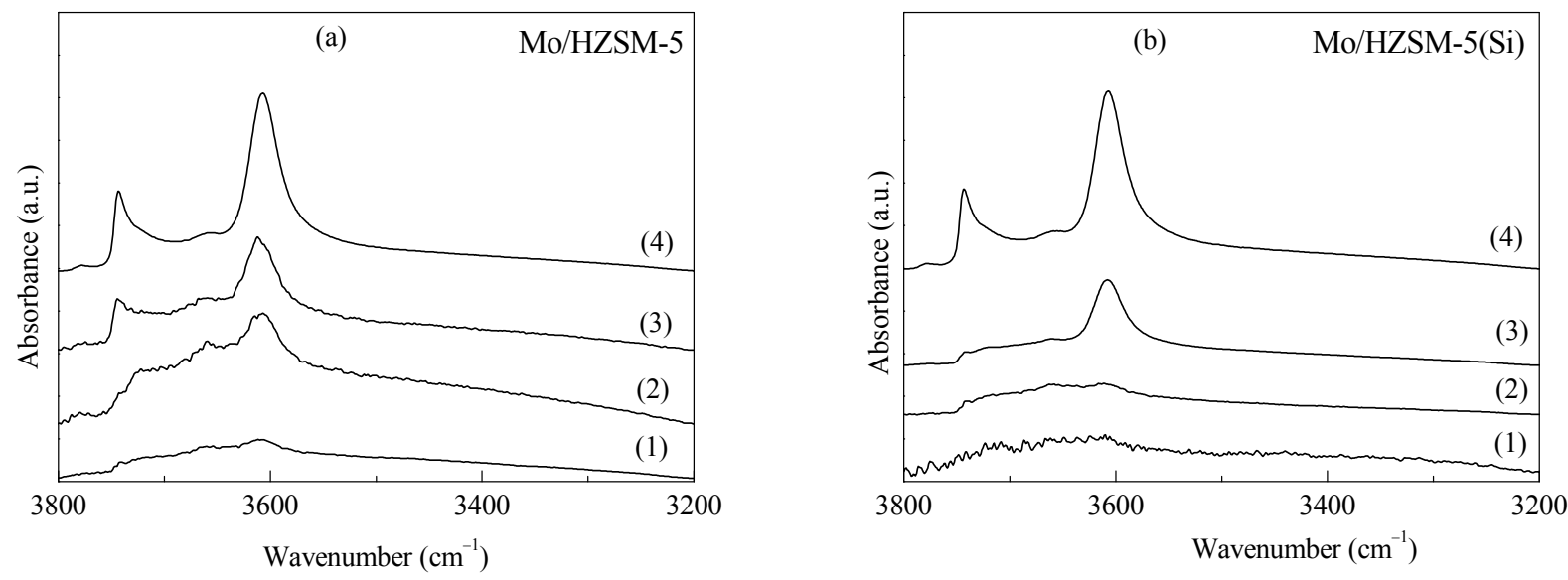

Fig. 5. FTIR spectra of non-silylated (a) and silylated Mo/HZSM-5 (b) catalysts. (1) Mo/HZSM-5 pretreated in He; (2) Mo/HZSM-5 pretreated in air; (3 fresh Mo/HZSM-5; (4) parent ZSM-5.

Table 3

Elemental compositions and benzene H/D exchange reaction rates of Mo/HZSM-5 and Mo/HZSM-5(Si) before and after precarburization.

\begin{tabular}{|c|c|c|c|c|c|c|c|}
\hline Sample & $\begin{array}{l}\text { Pretreatment } \\
\text { gas used }\end{array}$ & $\begin{array}{c}\mathrm{Al} \mathrm{a}^{\mathrm{a}} \\
\text { (wt\%) }\end{array}$ & $\begin{array}{c}\mathrm{Mo}^{\mathrm{a}} \\
\text { (wt\%) }\end{array}$ & $\begin{array}{l}\mathrm{Si} / \mathrm{Al}^{\mathrm{b}} \\
\text { (XPS) }\end{array}$ & $\begin{array}{l}\mathrm{Si} / \mathrm{Mo}^{\mathrm{b}} \\
\text { (XPS) }\end{array}$ & $\begin{array}{c}r_{\mathrm{C} 6 \mathrm{H} 6^{\mathrm{c}}} \\
(\mathrm{mmol} / \mathrm{min})\end{array}$ & $\begin{array}{l}\text { Relative H/D } \\
\text { exchange rate d }\end{array}$ \\
\hline HZSM-5 & - & 2.2 & $\infty$ & 22 & $\infty$ & 1.65 & 1.00 \\
\hline \multirow[t]{2}{*}{ Mo/HZSM-5 } & - & 1.9 & 3.4 & 27 & 3.5 & 1.30 & 0.79 \\
\hline & $\mathrm{CH}_{4} / \mathrm{He}$ & 1.9 & 3.2 & 24 & 8.1 & 0.79 & 0.48 \\
\hline \multirow[t]{2}{*}{ Mo/HZSM-5(Si) } & - & 1.9 & 3.4 & 28 & 3.2 & 1.35 & 0.82 \\
\hline & $\mathrm{CH}_{4} / \mathrm{He}$ & 1.8 & 3.2 & 28 & 8.1 & 0.47 & 0.28 \\
\hline
\end{tabular}

a Determined by ICP-OES.

${ }^{\mathrm{b}}$ Determined by XPS experiments.

cDetermined by catalytic H/D exchange reaction.

${ }^{d}$ Remaining $\mathrm{C}_{6} \mathrm{H}_{6}$ reaction rate relative to that of parent HZSM-5.

The external surfaces of the zeolite crystals were examined using X-ray photoelectron spectroscopy (XPS). The surface $\mathrm{Si} / \mathrm{Al}$ and Si/Mo ratios for the various catalysts are listed in Table 3. The Si/Al ratios of the Mo-modified zeolites before and after precarburization were similar to the values for the parent HZSM-5. The Si/Mo ratios increased on precarburization of Mo/HZSM-5 and Mo/HZSM-5(Si). This increase suggests agglomeration of the Mo phase during formation of the carbide phase. The agglomeration extents were similar for the two samples. Elemental analysis also shows that there was only a small loss of Mo during the activation step in methane.

The nature of the Mo phase was further investigated using UV Raman spectroscopy. The sample was excited with a 325 nm laser. The spectra are shown in Fig. 6. The spectrum of Mo/HZSM-5 has a broad absorption band extending over the $600-1000 \mathrm{~cm}^{-1}$ region, with more clearly defined bands at 860 and $960 \mathrm{~cm}^{-1}$. This spectrum resembles that of amorphous molybdenum oxide [45]. The weak band at $820 \mathrm{~cm}^{-1}$ is attributed to microcrystalline $\alpha-\mathrm{MoO}_{3}$ embedded in an amorphous molybdenum oxide matrix. The $380 \mathrm{~cm}^{-1}$ band characteristic of HZSM-5 is not observed for Mo/HZSM-5, because the molybdenum oxide phase covers a substantial part of the zeolite surface. The spectrum of Mo/HZSM-5(Si) is different from that of Mo/HZSM-5. The former spectrum contains bands at 280, 336, 820, and $995 \mathrm{~cm}^{-1}$; these show the presence of a much greater proportion of microcrystalline $\alpha-\mathrm{MoO}_{3}$. This spectrum also contains some features attributable to amor- phous molybdenum oxide. Bands from molybdenum oxides are not observed after carburization of Mo/HZSM-5, indicating that the particle surfaces were completely converted to molybdenum carbide. The weak peaks at 336 and $995 \mathrm{~cm}^{-1}$ indicate that a small amount of $\alpha-\mathrm{MoO}_{3}$ is retained in Mo/HZSM-5(Si, $\left.\mathrm{CH}_{4} / \mathrm{He}\right)$. The less extensive carburization in the silylated sample may be the result of higher dispersion of the initial molybdenum oxide phase [24].

TEM images of Mo/HZSM-5 (Fig. 7(a)) show that the mo-

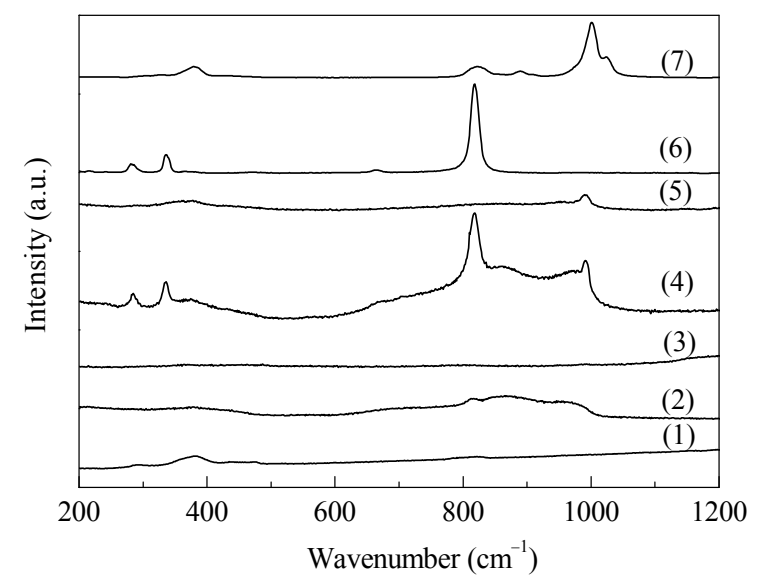

Fig. 6. UV Raman spectra of parent HZSM-5 (1), Mo/HZSM-5 (2), Mo/HZSM-5(CH 4 /He) (3), Mo/HZSM-5(Si) (4), Mo/HZSM-5(Si,CH $4 / \mathrm{He})$ (5), bulk $\mathrm{MoO}_{3}(6)$, and bulk $\mathrm{Al}_{2}\left(\mathrm{MoO}_{4}\right)_{3}$ (7). 
lybdenum oxide phase is present as small particles with typical diameters of $1 \mathrm{~nm}$. After precarburization, these particles become more clearly visible, because they are larger (Fig. 7(b)). This indicates that sintering occurred during the conversion of the molybdenum oxide particles to molybdenum carbide particles. This is in line with the XPS results. The images suggest that the particle size distribution also broadened during carburization. The TEM images confirm that the molybdenum oxide particles (Fig. 7(c)) are significantly smaller in silylated Mo/HZSM-5 than in non-silylated Mo/HZSM-5, in line with the discussion above. Similarly, carburization of Mo/HZSM-5(Si) led to sintering of these small particles to large molybdenum carbide particles (Fig. 7(d)).

Extensive characterization of the activated and spent catalysts indicated that pretreatment in air or He led to a larger fraction of molybdenum oxide species diffusing into the micropores than did activation in methane. This is supported by the ${ }^{27} \mathrm{Al}$ NMR and FTIR spectra. The mobility of molybdenum oxide species at high temperature, probably in the partially reduced form $\left(\mathrm{MoO}_{2}\right)$ [46], explains the decreased acidity. Although inspection of the hydroxyl region of the IR spectra indicates that after heating in air or He there are few acid sites left, the pyridine IR results show that the BAS density for these two samples is similar to that of the sample activated in methane. Accordingly, we suggest that the higher concentration of molybdenum oxide species in the micropores after He or air pretreatment results in faster deactivation, because the molybdenum carbide particles formed during MDA block the micropores. When the catalyst is activated in methane, less of the molybdenum oxide phase ends up in the micropores, because of the conversion of molybdenum oxides to molybdenum carbides. It has been reported that molybdenum carbides are less mobile than molybdenum oxides [47]. All these data provide a satisfactory explanation for the lower deactivation rate and improved stability in benzene selectivity of the precarburized catalysts. The conclusion that fewer BASs are accessible in the micropores is also supported by the higher ethylene selectivities of the He- and air-pretreated catalysts when the MDA activity decreases. The carbon speciation determined by TGA suggests that the formation in the micropores of soft coke from molybdenum carbides may explain the rapid deactivation of the He- or air-pretreated samples. Our explanation for the improved catalyst stability after pretreatment in methane is different from the previous claim that molybdenum carbides obtained by precarburization are more stable under MDA conditions than those formed during the MDA reaction $[32,48,49]$.

\section{Conclusions}

The effects of pretreatment of (silylated) Mo/HZSM-5 in various gas atmospheres (artificial air, $\mathrm{He}$, or a $\mathrm{CH}_{4} / \mathrm{He}$ mixture) at $973 \mathrm{~K}$ on their catalytic performances in MDA were investigated. Precarburization in methane gave catalysts with the highest aromatic selectivities and the lowest rates of catalyst deactivation. The benzene selectivity was the highest for the silylated Mo/HZSM-5 catalyst. Deactivation of the precarburized catalysts was less pronounced in the MDA reaction
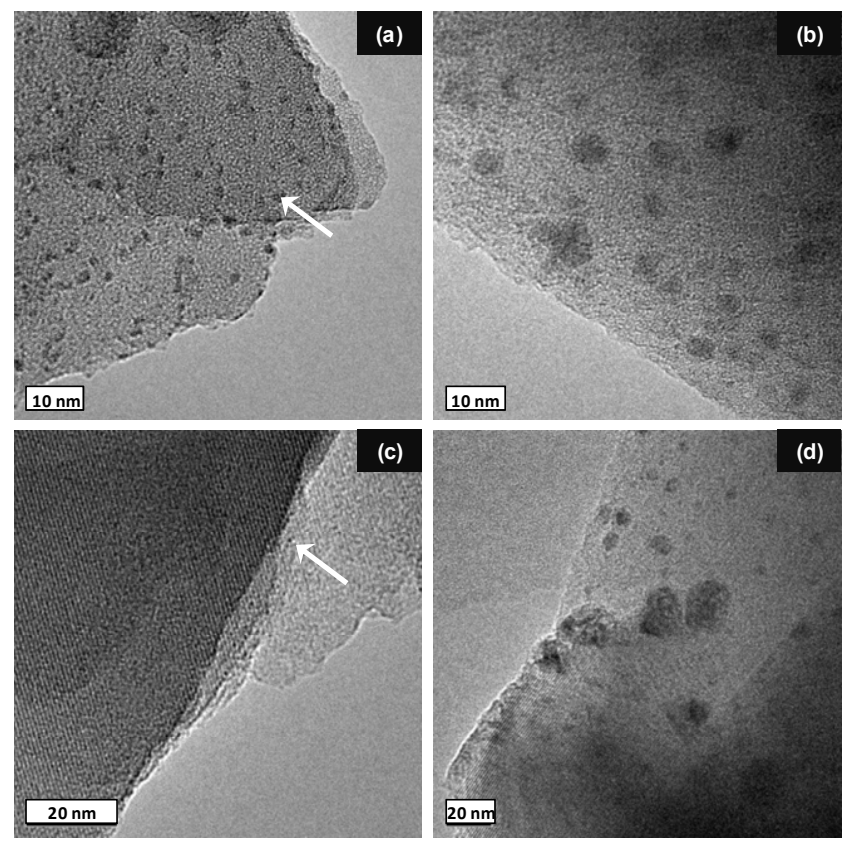

Fig. 7. TEM images of Mo/HZSM-5 (a), Mo/HZSM-5(CH $4 / \mathrm{He}$ ) (b), Mo/HZSM-5(Si) (c), and Mo/HZSM-5(Si,CH $4 / \mathrm{He})(\mathrm{d})$.

than for catalysts heated in air or He. This is because a greater amount of Mo diffuses into the zeolite micropores in the form of mobile molybdenum oxide species during heating in air or He than in heating in methane. Carburization of the molybdenum oxide particles present in the micropores resulted in molybdenum carbide particles, which contributed to pore blocking, making the BASs inaccessible. The deactivation can also be partly attributed to the formation of soft coke in the micropores, and is probably associated with the presence of molybdenum carbides. The more rapid formation of molybdenum carbides during heating in methane decreased the amount of mobile molybdenum oxide species and their diffusion into the micropores. It is argued that the presence of molybdenum carbide particles in the micropores contributes to rapid catalyst deactivation, in addition to the formation of hard coke on the external surface.

\section{Acknowledgments}

The authors thank Mr. Brahim Mezari for the ${ }^{27} \mathrm{Al}$ MAS NMR measurements.

\section{References}

[1] British Petroleum. BP Statistical Review of World Energy. London: BP, 2013

[2] Holmen A. Catal Today, 2009, 142: 2

[3] Sousa-Aguiar E F, Appel L G, Mota C. Catal Today, 2005, 101: 3

[4] Perego C, Bortolo R, Zennaro R. Catal Today, 2009, 142: 9

[5] Rostrup-Nielsen J R. Catal Today, 2002, 71: 243

[6] Zhang W P, Ma D, Han X W, Liu X M, Bao X H, Gao X W, Wang X S. J Catal, 1999, 188: 393

[7] Wang L S, Tao L X, Xie M S, Xu G F, Huang J S, Xu Y D. Catal Lett, 1993, 21: 35

[8] Xu Y D, Liu S T, Wang L S, Xie M S, Guo X X. Catal Lett, 1995, 30: 


\section{Graphical Abstract}

Chin. J. Catal., 2015, 36: 829-837 doi: 10.1016/S1872-2067(14)60301-6

\section{Activation of Mo/HZSM-5 for methane aromatization}

Christiaan H. L. Tempelman, Xiaochun Zhu, Emiel J. M. Hensen*

Eindhoven University of Technology, the Netherlands

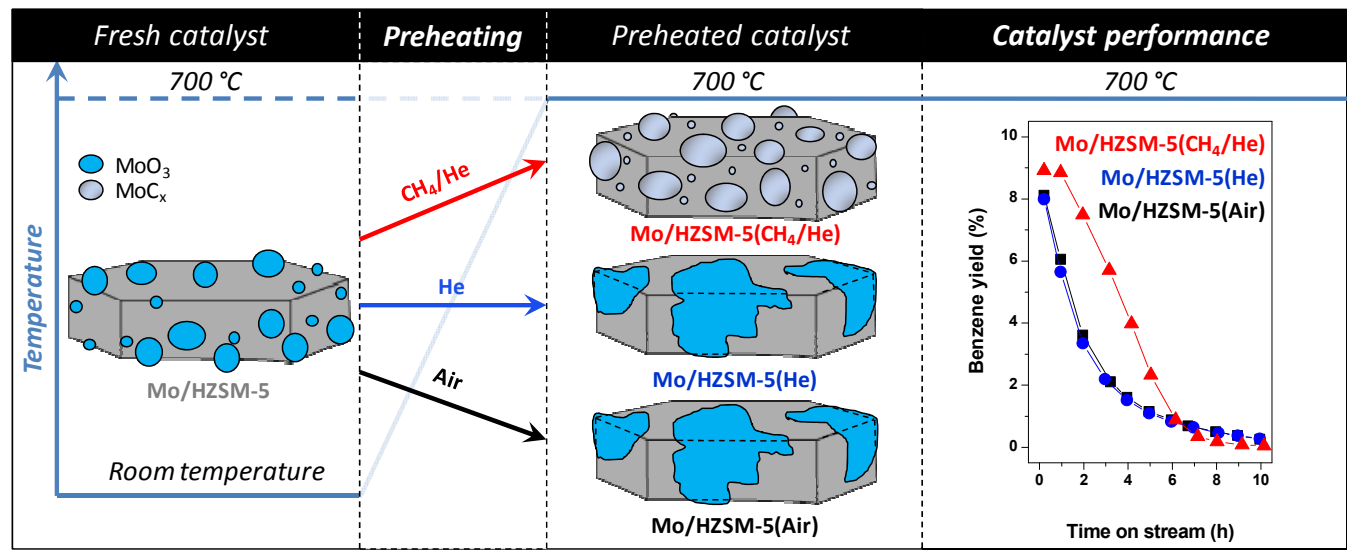

Carburization of Mo/HZSM-5 prevents dispersion of some of the molybdenum oxide particles into micropores, compared with activation in He or air. The molybdenum carbide particles formed in the micropores cause rapid deactivation of the micropore space, presumably by the formation of soft coke on the molybdenum carbides.

135

[9] Liu W, Xu Y, Wong S T, Wang L, Qiu J, Yang N. J Mol Catal A, 1997, 120: 257

[10] Majhi S, Mohanty P, Wang H, Pant K K. J Enery Chem, 2013, 22: 543

[11] Ren D M, Wang X S, Li G, Cheng X J, Long H Y, Chen L D. J Nat Gas Chem, 2010, 19: 646

[12] Ma S Q Guo X G, Zhao L X, Scott S, Bao X H. J Enery Chem, 2013, 22: 1

[13] Iliuta M C, Iliuta I, Grandjean B P A, Larachi F. Ind Eng Chem Res, 2003, 42: 3203

[14] Behrsing T, Jaeger H, Sanders J V. Appl Catal, 1989, 54: 289

[15] Su L L, Liu L, Zhuang J Q, Wang H X, Li Y G, Shen W J, Xu Y D, Bao X H. Catal Lett, 2003, 91: 155

[16] Chen L Y, Lin L W, Xu Z S, Li X S, Zhang T.J Catal, 1995, 157: 190

[17] Liu S, Wang L, Ohnishi R, Ichikawa M. Kinet Catal, 2000, 41: 132

[18] Weckhuysen B M, Rosynek M P, Lunsord J H. Catal Lett, 1998, 52: 31

[19] Ma D, Wang D Z, Su L L, Shu Y Y, Xu Y D, Bao X H. J Catal, 2002, 208: 260

[20] Descorme C, Gelin P, Lecuyer C, Primet A. Appl Catal B, 1997, 13: 185

[21] Ding W P, Meitzner G D, Iglesia E. J Catal, 2002, 206: 14

[22] Liu H M, Li Y, Shen W J, Bao X H, Xu Y D. Catal Today, 2004, 93 : 65

[23] Kikuchi S, Kojima R, Ma H T, Bai J, Ichikawa M. J Catal, 2006, 242: 349

[24] Tempelman C H L, de Rodrigues V O, van Eck E R H, Magusin P C M M, Hensen E J M. Microporous Mesoporous Mater, 2015, 203: 259

[25] Tempelman C H L, Hensen E J M. Unpublished results.

[26] Ismagilov Z R, Matus E V, Tsikoza L T. Energy Environ Sci, 2008, 1: 526

[27] Lacheen H S, Iglesia E. Phys Chem Chem Phys, 2005, 7: 538
[28] Shu J, Adnot A, Grandjean B P A. Ind Eng Chem Res, 1999, 38: 3860

[29] Shu Y Y, Ma D, Xu L Y, Xu Y D, Bao X H. Catal Lett, 2000, 70: 67

[30] Zhang C L, Li S A, Yuan Y, Zhang W X, Wu T H, Lin L W. Catal Lett, 1998, 56: 207

[31] Liu S T, Wang L S, Ohnishi R, Ichikawa M. J Catal, 1999, 181: 175

[32] Wang L S, Xu Y D, Wong S T, Cui W, Guo X X. Appl Catal A, 1997, 152: 173

[33] Wang D J, Lunsford J H, Rosynek M P. J Catal, 1997, 169: 347

[34] Jiang H, Wang L, Cui W, Xu Y, Catal Lett, 1999, 57: 95

[35] Zheng S R, Heydenrych H R, Jentys A, Lercher J A.J Phys Chem B, 2002, 106: 9552

[36] Lippens B C, de Boer J H. J Catal, 1965, 4: 319

[37] Datka J, Turek A M, Jehng J H, Wachs I E. J Catal, 1992, 135: 136

[38] Ma D, Shu Y Y, Bao X H, Xu Y D. J Catal, 2000, 189: 314

[39] Ma D, Shu Y Y, Cheng M J, Xu Y D, Bao X H. J Catal, 2000, 194: 105

[40] Solymosi F, Cserényi J, Szöke A, Bánsági T, Oszkó A. J Catal, 1997, 165: 150

[41] Tessonnier J P, Louis B, Rigolet S, Ledoux M J, Pham-Huu C. Appl Catal A, 2008, 336: 79

[42] Liu B S, Jiang L, Sun H, Au C T. Appl Surf Sci, 2007, 253: 5092

[43] Beck L W, Xu T, Nicholas J B, Haw J F. J Am Chem Soc, 1995, 117: 11594

[44] Hensen E J M, Poduval D G, Ligthart D A J M, van Veen J A R, Rigutto M S. J Phys Chem C, 2010, 114: 8363

[45] Haro-Poniatowski E, Julien C, Pecquenard B, Livage J, Camacho-López M A.J Mater Res, 1998, 13: 1033

[46] Borry III R W, Kim Y H, Huffsmith A, Reimer J A, Iglesia E. J Phys Chem B, 1999, 103: 5787

[47] Lacheen H S, Iglesia E. J Catal, 2005, 230: 173

[48] Liu H M, Bao X H, Xu Y D. J Catal, 2006, 239: 441

[49] Bouchy C, Schmidt I, Anderson J R, Jacobsen C J H, Derouane E G, Derouane-Abd Hamid S B. J Mol Catal A, 2000, 163: 283 